\title{
The Phonetics of Russian North Bylinas
}

Svetlana Tananaiko ${ }^{1}$, Marina Agafonova ${ }^{2}$

${ }^{1}$ Department of Phonetics, Saint-Petersburg State University, Russia

${ }^{2}$ Department of Phonetics, Saint-Petersburg State University, Russia

https://doi.org/10.36505/ExLing-2016/07/0040/000299

\begin{abstract}
The Internet site presenting the bylinas of Russian North from Sound Records Archives of Institute of Russian Literature was created in 2014. The aim of the site is to give free access to the unique Russian folklore sound records, made throughout XX century, for everybody interested, especially those who study anthropology, folklore, dialects and dialect phonetics of Russian, because on this site the presented sound fragments are analyzed in all these aspects. The article describes revealed phonetic characteristics of North bylinas and suggests a theoretical interpretation of the dynamics of the dialect phonetics changes.
\end{abstract}

Key words: dialect phonetics; Northern Russian dialect zone; Russian North bylinas

\section{The Internet Presentation of Russian Bylinas}

The Internet site "Corpus of Russian Folklore. Bylinas" presenting the bylinas of Russian North from Sound Records Archives of Institute of Russian Literature was created in 2014. The aim of the site is to give free access to the unique Russian folklore sound records, made throughout XX century, for everybody interested, especially those who study anthropology, folklore, dialects and dialect phonetics of Russian, because on this site the presented sound fragments are analyzed in all these aspects.

\section{The Phonetics of Russian North}

"Northern Russian Dialects, spread in the North and North-East of European Russia, and also in some regions of Siberia, have preserved a lot of archaic sound characteristics, which disappeared not only in Standard Russian, but also in Middle Russian and South Russian dialects. It can be explained both by linguistic and extra linguistic reasons, as well as by the specificity of colonization of Northern Russia, its peasant economy and peasant everyday life." (Tananaiko 2001).

The most specific characteristic of Northern Russian dialect zone is the set of phonemes different from other dialect zones. In the archaic Northern Russian dialect phonemic system there are more vowels and less consonants than in Standard Russian, what can be explained, on the one hand, by the preservation of special phonemes

ExLing 2016: Proceedings of $7^{\text {th }}$ Tutorial and Research Workshop on Experimental Linguistics, 27 June - 2 July 2016, Saint Petersburg, Russia 
replacing etymological yat and ancient /o/ under ascending tone, and on the other hand, by the absence of $/ \check{s}^{\prime}:$ / and the presence of only one affricate instead of two (Avanesov 1949).

Phonetic realization of vowels and consonants, even those common with Russian Standard, is in these dialects different from the Standard. The vowels are diphthongs or diphthongoids, the palatalized sibilants are lisping and so on (Meshchersky 1972).

The rules of phoneme distribution and the rules of alternations are also different from the Standard. For example, the unstressed vocalism retains unstressed /o/ and /e/, in the consonant system there are consonance simplifications $\left(/ \mathrm{mm} /\right.$ instead of $/ \mathrm{bm} /, / \mathrm{s}^{\prime} /$ instead of $/ \mathrm{s}^{\prime} \mathrm{t}^{\prime} /$ ) (Kolesov 2006).

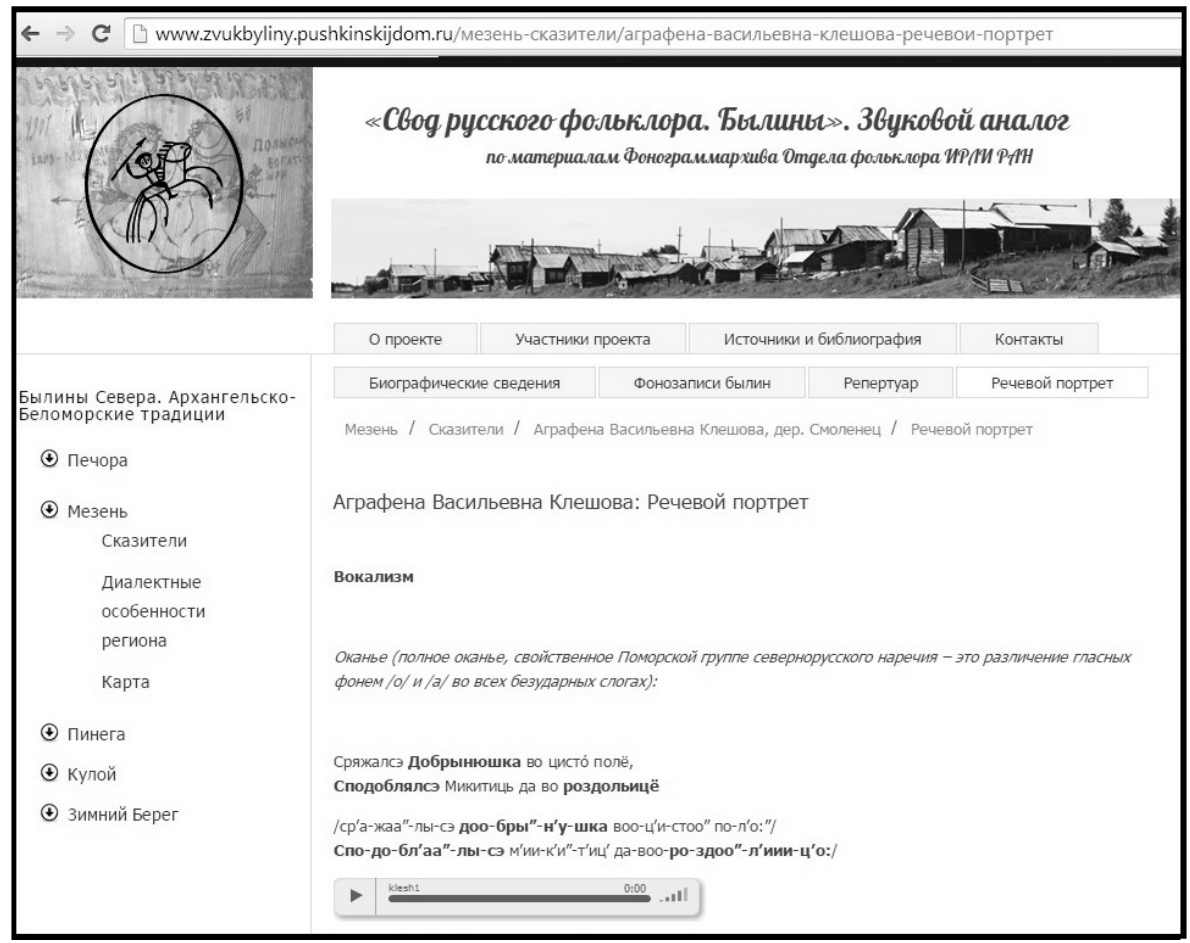

Figure. 1 The example of the presentation of a speech portrait of a bylina performer on the "Corpus of Russian Folklore. Bylinas. Sound Analogue" Internet site page. 


\section{The Material: Russian North Bylinas}

All these and many others Northern dialects characteristics can be traced in various texts, but in bylinas, traditional Russian heroic epics, known for preservation of the most established, typically traditional texts, least subject to changes because of their essential genre property, these characteristics are supposed to manifest themselves in their brightest. Apparently the very bylina genre, which belongs to folklore tradition, and is not supposed to contain any modern vocabulary, promotes the strongest possible retention of archaic phonetic features.

Bylina, known for preservation of the most established, archaic folklore language formulas and corresponding archaic language features, was developing in Russian folklore as a live genre until the middle of the XX century. So in spite of traditionalism, the bylinas phonetics couldn't help being influenced by modern linguistic processes which have been changing the phonetic aspect of folklore heritage.

The bulinas under study were recorded in Pechora and Mesen' region, both belonging to Pomor dialect group of Northern Russian dialect zone. The majority of these dialects retain the archaic pronunciation features, which are especially significant for the phonetic characteristic of these bylinas. The influence of modern language manifests itself in inconsistent realization of dialect features, random phonetically unjustified substitutions of some forms for others, that is, in the effects which usually indicate the destruction of the integral phonetic system of a dialect.

\section{The Results: Phonetical Features of the Bylinas}

The study of the material revealed a set of phonetic features, typical for these regions. It's important to mention that only segmental features were studied, because the traditional melodiousness, which is quite essential for the performance of bylinas, prevented any prosodic analysis. Generally the preservation and stability degree for the phonetic features characterizing the archaic northern dialects, is quite high.

The most persistent dialect features registered in the studied records were the retention of unstressed /o/ and /e/ - these two characteristics, which are essentially basic for Northern Russian vocalism, can be explained by the type of word stress, word rhythmic and the absence of vowel reduction in Northern dialects. The most persistent consonant feature is the specific use of affricates, when there is only one affricate in a dialect, either palatalized or velarized. These are the characteristics which are inevitably present in the pronunciation of all recorded performers. Also there are several morphological features, but their 
appearance is not as regular as of aforesaid characteristics, and each performer has their own set of morphological features.

From the point of view of theoretic linguistics, the results can be explained in the following way.

Language, perceived as a system of signs, is a complex self-organizing system, getting in the process of its development a definite functional structure and functioning as an entity. During the transition to new formations, for example during currently perceived swift, caused by various factors, destruction of Russian dialects, in the developing systems, that is, in the systems of language units of different levels, fluctuation amplitude growth will be traced, and it makes dialect systems, especially on phonetic level, rather chaotic, causes disappearance or neutralization of inherent phonetic oppositions and prosodic characteristics.

The results of the study show that the integral language system of these dialects is currently under destruction, and on phonetic level it is right to describe not a dialect phonetic system as a single whole, but to enumerate separate phonetic features, characterizing not only Pomor group dialects, but all the dialects of Northern dialect zone. The preservation of the very features, which are most inherent, most basic for the whole Northern dialect zone, reflects the progressive destruction of earlier phonemic oppositions.

In the end the various degrees of preservation and stability of different elements of the destroying phonetic systems demonstrate that even in faraway small Northern villages, where the records were made and where the performers were senior people, who recited the archaic text full of traditional formulas, - even there we witness the fast inevitable modifications of the sound form of speech, that reflect the language functioning dynamics in dialects.

\section{References}

Avanesov R. 1949. Essays of Russian Dialectology. Moscow.

Corpus of Russian Folklore. Bylinas. Sound Analogue: Internet site. URL: http://www.zvukbyliny.pushkinskijdom.ru/.

Kolesov V. et al. 2006. Russian Dialectology. Moscow.

Meshchersky M. (ed.) 1972. Russian Dialectology. Moscow.

Tananaiko S. 2001. Russian Dialects in Non-Slavonic Surrounding. In Verbitskaya L., Vasilkova V., Kozlovsky V., Skvortsov N. (eds.), Comparative Collection: Miscellany of Sociological and Humanitarian Studies, 173-185, Saint-Petersburg. 